\title{
STUDI KOMPARASI PEMBELAJARAN KIMIA MENGGUNAKAN MODEL KOOPERATIF TIPE COURSE REVIEW HOREY DAN MIND MAPPING TERHADAP HASIL BELAJAR SISWA
}

\author{
Erin Junita*, Rosa Murwindra dan Asregi Asril \\ Program Studi Pendidikan Kimia, Fakultas Tarbiyah dan Keguruan (FTK), Universitas Islam \\ Kuantan Singingi (UNIKS), Teluk Kuantan, Riau, Indonesia
}

\begin{tabular}{l}
\hline \multicolumn{1}{c}{ Informasi Artikel } \\
\hline Sejarah Artikel: \\
Diterima 15 November 2018 \\
Disetujui 22 Juli 2019 \\
Dipublikasikan 25 Juli 2019 \\
\hline Keywords: \\
Comparison,Course Review \\
Horey, \\
Mind Mapping, \\
Result Of Learning, \\
Colloid System. \\
\end{tabular}

\begin{abstract}
Abstrak
Tujuan penelitian untuk mengetahui perbedaan hasil belajar siswa menggunakan metode pembelajaran Course Review Horey (CRH) dengan metode pembelajaran Mind Mapping. Populasi pada penelitian ini adalah seluruh siswa kelas XI IPA di SMA N 1 Hulu Kuantan. Sampel diambil dengan cara cluster random sampling berjumlah 2 kelas. Pengumpulan data menggunakan soal tes. Analisis data menggunakan uji Nonparametrik Mann-Whitney. Berdasarkan hasil penelitian diperoleh nilai Asymp. Sig. (2-tailed) adalah 0,004<0,05 sehingga terdapat perbedaan hasil belajar siswa menggunakan metode pembelajaran Course Review Horey dengan metode pembelajaran Mind Mapping. Sehingga dapat diselidiki lebih lanjut perbedaan hasil belajar dengan memacu pada rerata nilai posttest. Hasil belajar kelas yang menggunakan metode CRH lebih tinggi daripada metode mind mapping.
\end{abstract}

\begin{abstract}
The purpose of this study is to determine the differences in student learning outcomes using the y Course Review Hore (CRH) learning method with the Mind Mapping learning method. The population in this study are all students of class XI Science in SMA N 1 Hulu Kuantan. Samples taken by cluster random sampling amount to 2 classes. Data collection uses test questions. Data analysis uses the Mann-Whitney Nonparametric test. Based on the results of the study obtain the value of Asymp. Sig. (2-tailed) is $0.004<0.05$ so there are differences in student learning outcomes using the Course Review Horey learning method with the Mind Mapping learning method. So that further differences in learning outcomes can be investigated by spurring on the average post-test scores. Class learning results that use the CRH method are higher than the mind mapping method.
\end{abstract}

(C) 2019 Universitas Riau

* E-mail: erinjunita@gmail.com

No. Telp: 085384882687

\section{PENDAHULUAN}

Tujuan pendidikan nasional pada dasarnya mencerdaskan kehidupan bangsa dan mengembangkan manusia Indonesia seutuhnya. Komponen yang terpenting untuk dapat mewujudkan tujuan pendidikan nasional tersebut salah satunya dengan adanya proses belajar mengajar yang efektif agar nantinya pesan yang disampaikan dalam proses tersebut 
dapat diterima dengan baik dan hasilnya sesuai dengan yang diharapkan (Azhar, 2007).Untuk mewujudkan pembelajaran yang baik guru dituntut dapat menciptakan pembelajaran yang menyenangkan, menerapkan model dan membuat pelajaran mudah dimengerti oleh siswa, serta menyenangkan bagi siswa sehingga nantinya akan mendapatkan hasil sesuai dengan yang diharapkan (Sa'ud, 2009).

Berdasarkan observasi dan wawancara awal penulis ke SMA Negeri 1 Hulu Kuantan terdapat beberapa permasalahan yang di temukan. Pertama, guru hanya menerapkan satu model pembelajaran yaitu Teacher Center Learning dan belum pernah menerapkan model pembelajaran lainnya sehingga proses pembelajaran masih terpusat pada guru sedangkan siswa hanya mendengar dan mencatat sesuai dengan apa yang diperintahkan yang berakibat siswa cenderung pasif dan keaktifan siswa di dalam kelas masih rendah. Kedua, banyak siswa yang kurang bersemangat dalam mengikuti pembelajaran khususnya pada materi sistem koloid yang sebagian besarnya merupakan materi hafalan. Kurangnya minat siswa dalam pelajaran yang menyebabkan rendahnya hasil belajar siswa. Ketiga, dilihat dari hasil ulangan siswa kelas XI IPA 1 pada materi koloid tahun pelajaran 2016/2017, dari 20 orang siswa hanya 7 orang atau 30\% yang memenuhi Kriteria Ketuntasan Minimal dan 13 orang siswa atau sebesar $70 \%$ yang tidak memenuhi Kriteria Ketuntasan Minimal, adapun Kriteria Ketuntasan Minimal yang ditetapkan oleh sekolah untuk mata pelajaran kimia adalah 75 .

Model pembelajaran kooperatif tipe Course Review Horey (CRH) adalah salah satu tipe pembelajaran kooperatif yang menekankan adanya kerja sama antara anggota kelompok untuk mencapai tujuan belajar. Terdapat empat tahapan dalam model pembelajaran CRH yaitu, mengajar, belajar kelompok, turnamen, yel-yel, prestasi kelompok (Suprijono, 2009). CRH menurut (Suyatno,2009) dapat mendorong siswa untuk ikut aktif dalam belajar. Menurut penelitian (Kharismawan dan Haryani, 2015) mengunakan metode Course Review Horey dengan hasil didapatkan presentasi 26,23\% dapat meningkatkan hasil belajar kimia siswa.

Model pembelajaran kooperatif Mind Mapping merupakan model yang memanfaatkan otak siswa sebagai pusat untuk memperoleh informasi yang sedang dipelajari. Model ini menuntun siswa untuk memetakan pemikirannya terhadap materi, sehingga mudah untuk dipahami dan diingat. Mind Mapping adalah model pembelajaran yang menuangkan atau mengubah materi menjadi kelompok-kelompok peta pikiran berdasarkan kreativitas siswa itu sendiri tanpa bantuan guru (Buzan, 2010). Adapun langkah membuat Mind Mapping yakni kertas kosong tak bergaris, pena dan pensil warna, otak serta imajinasi atau pemikiran. Penelitian yang dilakukan oleh (Aprianto, 2014) dengan metode Mind Mapping dengan hasil prestasi belajar siswa yang dibuktikan berdasarkan rerata marginal pada siswa yang diberi metode Mind Mapping adalah 73,134 sedangkan pada siswa yang diberi metode konvensional adalah 55,717.

Berdasarkan penelitian di atas terlihat adanya peningkatan hasil belajar menggunakan metode Course Review Horey dan Mind Mapping. Berdasarkan latar belakang tersebut maka penulis tertarik untuk melakukan penelitian untuk mengetahui 
perbedaan hasil belajar antara metode Course Review Horey dan Mind Mapping pada pembelajaran kimia.

\section{METODE PENELITIAN}

Penelitian yang dilakukan yaitu penelitian komparatif atau penelitian yang bersifat membandingkan keberadaan suatu variabel atau lebih pada dua sampel yang berbeda. Penelitian ini menggunakan pendekatan eksperimen yaitu suatu penelitian yang digunakan untuk mencari pengaruh perlakuan tertentu terhadap yang lain dalam kondisi yang terkendali (Prasetio, 2014). Variabel bebas pada penelitian ini adalah metode pembelajaran Course Review Horey dan Mind Mapping sedangkan variabel terikatnya yaitu hasil belajar siswa. Populasi pada penelitian ini adalah seluruh siswa yang berada di SMA Kuantan Hulu. Sampel penelitian ini adalah 2 kelas XI yang diambil dengan teknik cluster random sampling (Sugiono, 2008).

Uji homogenitas dilakukan menggunakan uji $\mathrm{F}$ pada taraf signifikan $(\alpha=0,01)$ dengan kriteria pengujian $F_{\text {hitung }}<\mathrm{F}_{\text {tabel. }}$ Uji homogenitas sampel dilakukan untuk mengetahui bahwa kelas yang akan dijadikan sampel mempunyai varians yang homogen. Dari hasil perhitungan dengan menggunakan uji F, didapatkan untuk kedua kelas $F_{\text {hitung }}<$ Ftabel. Ini berarti kedua kelas dinyatakan homogen. Kelas XI IPA 1 yang menjadi kelas eksperimen I yang menerapkan model pembelajaran Course Review Horey dan kelas XI IPA 2 yang menjadi kelas ekperimen II yang menerapkan model pembelajaran Mind Mapping.

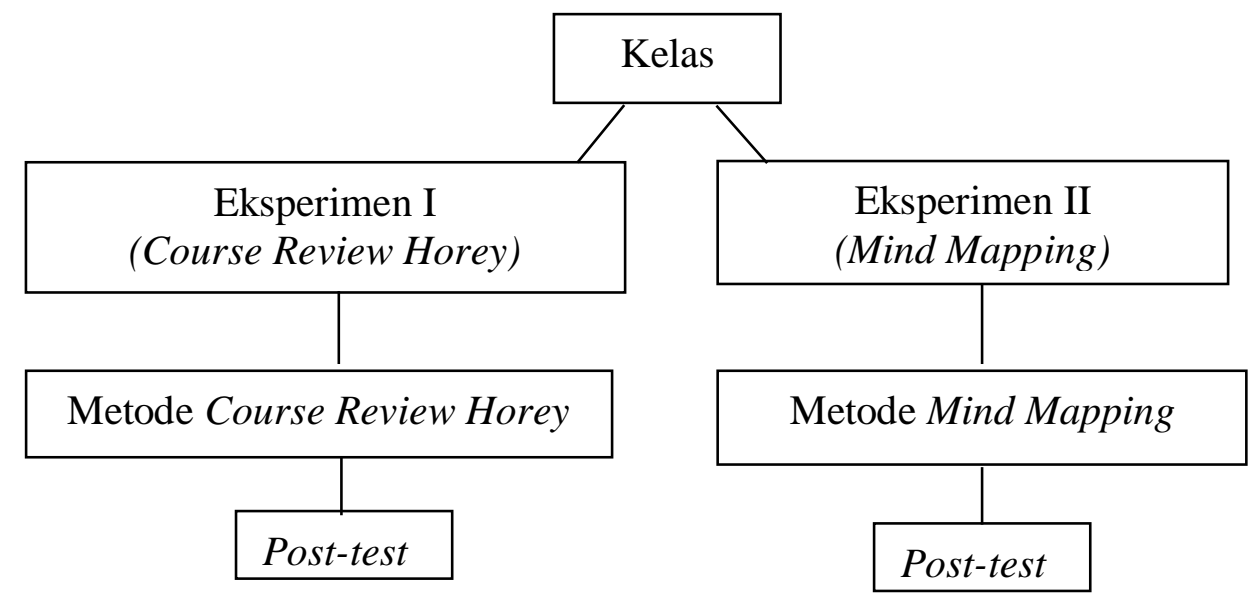

Gambar 1. Bagan Desain Penelitian

Teknik pengumpulan data yang dilakukan dengan menggunakan tes berupa pemberian post-test. Instrumen tes yang digunakan berupa soal objektif sebanyak 50 butir soal yang telah melalui tahap uji validitas, reabilitas, uji daya beda, uji tingkat kesukaran serta analisis distraktor (Hartono, 2008). Dari hasil pengujian baik itu uji uji validitas, reliabelitas, uji daya beda, uji tingkat kesukaran serta analisis distraktor didapatkan hasil 25 
soal yang memenuhi kriteria yang dibutuhkan sebagai soal post test. Adapun bentuk desain eksperimen yang digunakan pada penelitian ini adalah Posttest-Only Control Desigen, dapat dilihat pada Bagan gambar 1.

Uji parametrik digunakan karena pada uji ini tidak mengunakan parameterparameter tertentu seperti mean, standar deviasi, varian, dan tidak mensyaratkan data berdistribusi normal (Priyatno, 2012).Dengan taraf signifikansi $\alpha=5 \%$, Statistik uji yang digunakan :

$$
Z^{*}=\frac{U_{I}-\bar{X}_{U}}{S_{U}}
$$

Kriteria Pengujian

Jika signifikansi $\leq 0,05$ maka $\mathrm{H}_{0}$ ditolak

jika signifikansi $>0,05$ maka $\mathrm{H}_{0}$ diterima.

\section{HASIL DAN PEMBAHASAN}

\section{a. Hasil Penelitian}

Data dalam penelitian ini adalah nilai yang diperoleh oleh sampel pada kelas eksperimen I dan kelas ekperimen II setelah diberikan post-test. Pada gambar 2 dapat dilihat hasil post-test kelas ekspeimen I.

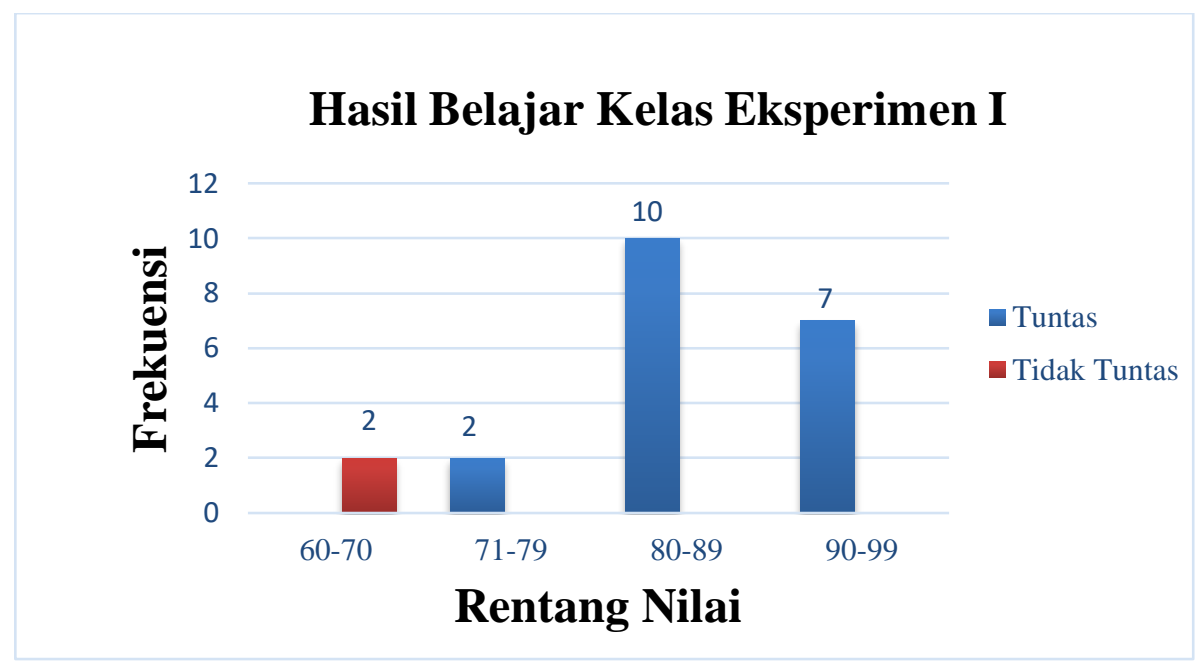

Gambar 2. Hasil Post Test Kelas Eksperimen I

Dari Gambar 2 di atas dapat dilihat bahwa pada kelas eksperimen I yang diberi perlakuan berupa penerapan model pembelajaran Course Review Horey diperoleh hasil 10\% siswa tidak lulus dan $90 \%$ siswa lulus dengan rincian dari 21 siswa terdapat 19 orang siswa lulus diatas nilai Krikteria Ketuntasan Minimal yaitu 75 dan 2 orang siswa yang berada dibawah Krikteria Ketuntasan Minimal.

Berdasarkan gambar 3 di atas dapat disimpulkan bahwa setelah diberikan perlakuan berupa penerapan model pembelajaran Mind Mapping di kelas eksperimen II diperoleh 
hasil $81 \%$ siswa lulus serta $19 \%$ siswa tidak lulus dengan rincian dari 21 orang siswa terdapat 17 orang siswa lulus diatas Krikteria Ketuntasan Minimal 75 dan 4 orang siswa yang berada dibawah Krikteria Ketuntasan Minimal.

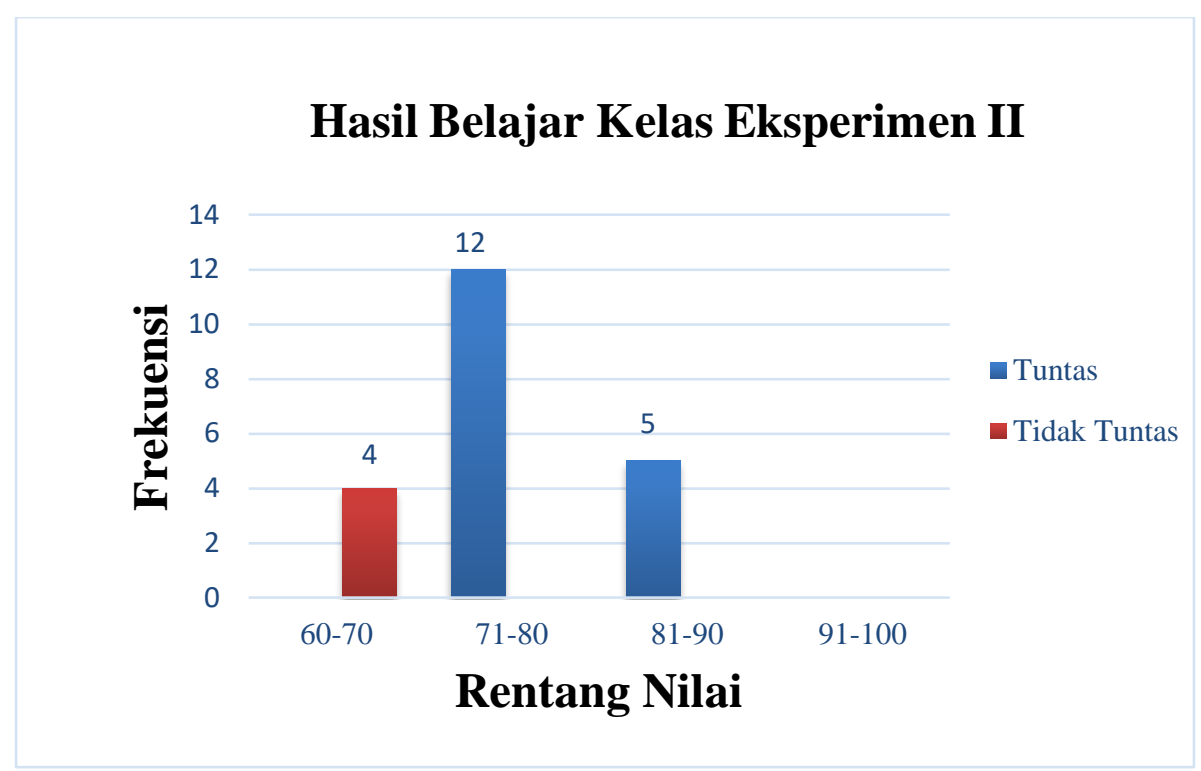

Gambar 3. Hasil Post-Test Kelas Ekperimen II

\section{b. Pembahasan}

Penelitian studi komparasi ini dilakukan untuk membandingkan hasil belajar siswa setelah diterapkan model pembelajaran koopertif tipe Course Review Horey di kelas eksperimen I dan model pembelajaran Mind Mapping di kelas eksperimen II. Model pembelajaran $C R H$ merupakan cara belajar mengajar yang lebih menekankan pada pemahaman materi yang diajarkan dengan menyelesaikan soal-soal (Huda, 2011). Penerapan model yang tepat merupakan salah satu strategi guru untuk dapat meningkatkan hasil belajar siswa (Hamdani, 2011). Sementara Mind Mapping adalah Pembelajaran dengan cara merangkum untuk dapat meningkatkan prestasi belajar dan kreativitas siswa dalam berfikir kreatif (Sulistyowati, 2012). Menurut (Buzan, 2009) pembelajaran Mind Mapping akan mempermudah siswa dalam perencanaan, berkomunikasi, siswa menjadi lebih kreatif, siswa mudah menyelesaikan masalah, memusatkan perhatian, siswa mampu menyusun dan menjelaskan pikiran-pikiran, mengingat dengan lebih baik, belajar lebih cepat dan efisien, dan melatih "gambar keseluruhan".

Untuk mengetahui perbandingan kedua metode pembelajaran dilakukan perhitungan berdasarkan data hasil belajar siswa menggunakan uji Mann-Whitney. Adapun hasil dari perhitungan uji nonparametrik Mann-Whitney dapat dilihat dari Tabel 1. Dari Tabel 1 di bawa untuk menguji hipotesis dapat dilihat dari tabeldengan membandingkan nilai signifikansi 5\% yaitu 0,05 dengan Asymp. Sig. (2-tailed) =0,004, sehingga hasilnya adalah 0,004 $<0,05$ membuktikan jika $\mathrm{H}_{0}$ ditolak. Hal ini menunjukkan bahwa terdapat perbedaan hasil belajar siswa menggunakan metode $C R H$ dengan metode Mind Mapping. Perbedaan lebih lanjut dilihat dari rerata post-tes kedua kelas tersebut. Kelas yang 
menggunakan metode $C R H$ memiliki nilai rerata post-tes lebih tinggi daripada kelas yang menggunakan metode Mind Mapping. Hal ini sesuai dengan penelitian yang dilakukan oleh petrianis dengan hasil penelitian Course Review Horay dapat meningkatkan prestasi belajar siswa pada pokok bahasan koloid dengan koefesien pengaruh sebesar 4,32\% (Petrianis, 2009). Sama halnya dengan penelitian yang dilakukan oleh Kharismawan dengan hasil temuan 26\% dapat meningkatkan hasil belajar siswa (Kharismawan, 2015). Metode $C R H$ lebih menekankan siswa menguasaan materi melalui penyelesaian soal secara mandiri dan aktif dalam pembelajaran.

Tabel 1. Hasil Uji Perbedaan Kedua Metode

\begin{tabular}{lr}
\hline Test Statistics $^{\boldsymbol{a}}$ & NILAI \\
\hline Mann-Whitney U & 107,000 \\
\hline Wilcoxon W & 338,000 \\
\hline Z & $-2,916$ \\
\hline Asymp. Sig. (2-tailed) &, 004
\end{tabular}

\section{KESIMPULAN DAN SARAN}

\section{a. Kesimpulan}

Terdapat perbedaan hasil belajar siswa yang menggunakan metode $C R H$ dan metode Mind Mapping pada pembelajaran kimia. Hasil belajar siswa yang diajarkan menggunakan metode $C R H$ lebih tinggi dibandingkan dengan menggunakan Mind Mapping. Metode $C R H$ mampu meningkatkan hasil belajar siswa dengan lebih menekankan penguasaan konsep melalui soal-soal, sehingga siswa dapat aktif dan mandiri untuk menguasai materi.

\section{b. Saran}

Saran yang ingin saya sampaikan kepada guru kimia khususnya yang berada di SMAN 1 Hulu Kuantan. Pertama, untuk menerapkan metode yang menarik agar peserta didik tertarik untuk mengikuti pelajaran. Kedua, sebaiknya pihak sekolah dapat menyiapkan sarana dan prasarana penunjang untuk memudahkan guru menerapkan metode-metode yang terbaru. Ketiga, sebaiknya guru lebih sering membaca dan mencari referensi metode mengajar terbaru.

\section{DAFTAR PUSTAKA}

Apriyanto, D, Mulyani dan Susanti, E. 2014. Pengaruh metode pembelajaran mind mapping dan kemampuan memori siswa terhadap prestasi belajar kimia pada pokok bahasan hukum-hukum dasar kimia pada siswa kelas X Semester Gasal di SMA 
Negeri 1 Mojolaban Tahun Pelajaran 2012/2013. Jurnal Pendidikan Kimia. 3(3): 110.

Azhar, A. 2007. Media pembelajaran. PT. Raja Grafindo Persada. Jakarta:

Buzan, T. 2009. Buku Pintar Mind Mapping. PT. Gramedia Pustaka Utama. Jakarta

Hamdani. 2011. Strategi belajar Mengajar. CV. Pustaka Setia. Bandung

Hartono. 2008. SPSS 16.0 Analisis Data Statistika dan Penelitian. Pustaka Belajar. Yogyakarta.

Huda, M. (2011). Cooperative learning (Vol. 113). Pustaka Pelajar. Yogyakarta

Kharismawan, B., dan Haryani, S. 2015. Penerapan Metode Pembelajaran Course Review Horay Berbasis Problem Posing Terhadap Hasil Belajar. Chemistry in Education. 4(1): 31-38

Petrianis, P., Erna, M. E., \& Amran, E.Y.A.Y. 2015. Penerapan model pembelajaran kooperatif course review horay untuk meningkatkan prestasi belajar siswa pada pokok bahasan koloid di kelas XI IPA SMA Negeri 4 Pekanbaru. Jurnal Online Mahasiswa Fakultas Keguruan dan Ilmu Pendidikan Universitas Riau. 2(2): 1-9.

Saud, U.S dan Makmun, A.S. 2009. Perencanaan Pendidikan. Remaja Rosda Karya. Bandung

Sugiyono. 2008. Metode penelitian pendidikan:(pendekatan kuantitatif, kualitatif dan $R \&$ $D)$. Alfabeta. Bandung

Suprijono, A. (2009). Cooperative learning: teori \& aplikasi PAIKEM. Pustaka Pelajar. Yogyakarta

Suyatno. (2009). Menjelajah Pembelajaran Inovatif. Masmedia. Siduarjo

Priyatno, D. (2012). Cara kilat belajar analisis data dengan SPSS 20. Andi Offset. Yogyakarta

Sulistyowati, D. (2012). Pengaruh teknik pembelajaran mind mapping terhadap prestasi dan kreativitas belajar kimia siswa kelas XI SMAN 2 Malang. SKRIPSI Jurusan Teknologi Pendidikan-Fakultas Ilmu Pendidikan, Universitas Malang. Malang. 